Dinamika Kesehatan Jurnal Kebidanan dan Keperawatan Vol 10 No. 1 Juli 2019 (ISSN: 2086-3454 EISSN: 2549-4058)

url: http://ojs.dinamikakesehatan.unism.ac.id DOI : https://doi.org/10.33859/dksm.v10i1

Determinan Pemilihan Tempat Persalinan di PuskesmasTapin Utara

\title{
Determinan Pemilihan Tempat Persalinan di Puskesmas Tapin Utara
}

\author{
Lisda Handayani *1, Elvine Ivana Kabuhung1, Yunita Afriani \\ *1Universitas Sari Mulia \\ *lisdada.sm@gmail.com
}

DOI: https://doi.org/10.33859/dksm.v10i1.406

\begin{abstract}
Abstrak
Latar Belakang: Salah satu indikator persalinan bersih dan aman adalah pertolongan ditolong tenaga kesehatan di fasilitas kesehatan (faskes). Standar Pelayanan Minimal (SPM) bidang kesehatan tahun 2016 menyatakan target persalinan sesuai standar adalah 100\%, sedangkan data Puskesmas tapin Utara menyebutkan persalinan di faskes sebesar 56,8\% dan non faskes Sebanyak 43,2\%. Dari data yang didapat disimpulkan bahwa persalinan di wilayah puskesmas Tapin Utara belum mencapai target SPM bidang kesehatan.

Tujuan: Menganalisis determinan pemilihan tempat persalinan oleh ibu bersalin diwilayah puskesmas Tapin Utara.

Metode: Penelitian Kuantitatif dengan pendekatan cross sectional. Pengambilan sampel dengan tekhnik total sampling sebanyak 62 ibu bersalin selama januari 2017. Analisis bivariat digunakan Uji chi square dan analisis multivariat regresi lostik berganda

Hasil: Gambaran pemilihan tempat persalinan oleh ibu bersalin diwilayah puskesmas tapin utara adalah ibu bersalin di faskes $(43,5 \%)$ dan non faskes $(56,5 \%)$. Determinan pemilihan tempat persalinan adalah budaya $(\mathrm{p}=0,000)$, Pemeriksaan Kehamilan $(\mathrm{p}=0,001)$, pengetahuan $(\mathrm{p}=0,000)$, dan Biaya persalinan $(\mathrm{p}=0,001)$, sedang yang bukan merupakan determinan pemilihan tempat persalinan adalah pendapatan $(\mathrm{p}=0,154)$, akses ibu ke faskes $(\mathrm{p}=0,207)$ dan dukungan keluarga $(\mathrm{p}=0,439)$. Determinan paling dominan adalah biaya persalinan $(\mathrm{p}=0,008, \mathrm{OR}=11,712)$.

Simpulan: Determinan pemilihan tempat persalinan di wilayah puskesmas tapin utara adalah budaya, pemeriksaan kehamilan, pengetahuan dan biaya sedangkan yang bukan determinan adalah pendapatan, akses ke faskes dan dukungan keluarga. Determinan paling dominan adalah biaya persalinan.
\end{abstract}

Kata kunci: Tempat Persalinan, Budaya, Pemeriksaan Kehamilan, Pengetahuan, Pendapatan, Biaya Persalinan, Akses ibu ke Faskes dan dukungan keluarga. 


\title{
Determinant Choice Of Delivery At The North Tapin Health Center
}

\begin{abstract}
Background: Maternal mortality rate still high because delivery is not at health facilities. Information of north tapin central public health said there had been 470 delivery and while non health facilities about 43,2 \% .For which figures obtained concludea that delivery in district tapin not reached target public health years 2016 who was targeted delivery service at health facilities appropriate standard $100 \%$ service.

Objective: analysis determinant factors relating to the selection of the place of birth in the puskesmas Tapin utara.

Methods: Quantitative research by approach cross sectional. Sampling used total sampling about 62 delivered in january 2017. The stastik used is chi square and regression lostik simple.

Result: there are 43,5\% mother who has deivery at health care facilities, while the non health care facilities are $56.5 \%$. Correlation factors of cultural deals namely $p=0,000$ value, the anc $p=0,001$ value, $p$ value knowledge $=0,000$, delivery fees $p=0,001$ value, $p$ income $=0,154$ value, mother access to health care facilities $p=0,315$ value, and support the family $p=0,411$ value. Value the ordi highest of the results of the test stastik safinat logistic regression simple namely the cost factor of 11,712 childbirth.

Conclusion: The result of 7 factor in some 4 factors that there are dealing with the selection namely the delivery: cultural factors, a pregnancy, knowledge, and the delivery fee. The cost factor a factor most dominant dealing with the selection the delivery
\end{abstract}

Keywords: The delivery, culture, pregnancy, knowledge, income, the delivery fee, access health care, support by family

\section{PENDAHULUAN}

Kebijakan Kementerian Kesehatan

dalam dekade terakhir menekankan agar

setiap persalinan ditolong oleh tenaga

kesehatan dalam rangka menurunkan

kematian ibu dan kematian bayi. Meskipun

persalinan ditolong oleh tenaga kesehatan

tetapi tidak dilaksanakan di fasilitas pelayanan

kesehatan, dianggap menjadi salah satu

penyebab masih tingginya Angka Kematian
Ibu (AKI). Rencana Strategis Kementerian

Kesehatan tahun 2015-2019 menetapkan

persalinan di fasilitas pelayanan kesehatan

sebagai salah satu indikator upaya kesehatan

ibu, menggantikan pertolongan persalinan

oleh tenaga kesehatan dituangkan dalam

Peraturan menteri Kesehatan no. 43 tahun

2016 tentang Standard Pelayanan Minimal

(SPM) dalam bidang kesehatan yang

menyebutkan bahwa pelayanan kesehatan ibu 
Dinamika Kesehatan Jurnal Kebidanan dan Keperawatan Vol 10 No. 1 Juli 2019 (ISSN: 2086-3454 EISSN: 2549-4058) url: http://ojs.dinamikakesehatan.unism.ac.id DOI : https://doi.org/10.33859/dksm.v10i1

Determinan Pemilihan Tempat Persalinan di PuskesmasTapin Utara

bersalin harus sesuai standard pelayanan persalinan (Kemenkes RI, 2015).

Pelayanan persalinan sesuai standar adalah persalinan yang dilakukan oleh bidan dan atau dokter Spesialis kebidanan yang bekerja di fasilitas pelayanan kesehatan pemerintah ataupun swasta yang memiliki surat tanda Registrasi (STR). Fasilitas kesehatan meliputi polindes, Poskesdes, Puskesmas, bidan praktek swasta, klinik pratama, klinik utama, klinik bersalin, balai kesehatan ibu dan anak, rumah sakit pemerintah maupun swasta. Cakupan kinerja yang di harapkan pemerintah adalah 100\% pelayanan persalinan sesuai standar (Kemenkes, 2016).

Menurut data dari Dinas Kesehatan Kabupaten Tapin 3.155 persalinan tenaga kesehatan di kabupaten Tapin, 764 (24,2 \%) persalinan dilakukan di RS, 608 (19,3\%) persalinan di RS swasta/ RSIB/ Klinik, 202 $(6,4 \%)$ di pustu/ poskesdes/ polindes, dan $1.581(50,1 \%)$ persalinan nakes di non Fasilitas pelayanan kesehatan atau rumah Ibu.
Dari data yang di dapat dapat disimpulkan bahwa bahwa persalinan di kabupaten Tapin belum mencapai target SPM bidang kesehatan tahun 2016 yang menargetkan pelayanan persalinan sesuai standard pelayanan $100 \%$. Tujuan dari penelitian ini adalah untuk mengetahui determinan pemilihan tempat persalinan oleh ibu bersalin di Puskesmas Tapin Utara Kabupaten Tapin.

\section{BAHAN DAN METODE}

Penelitian ini menggunakan penelitian kuantitatif dengan pendekataan cross sectional. Populasi dalam penelitian ini adalah seluruh ibu bersalin pada bulan Januari tahun 2017 dan bertempat tinggal diwilayah kerja puskesmas Tapin Utara. Tekhnik sampel adalah total sampling yaitu seluruh persalinan di bulan Januari tahun 2017 sebanyak 62 orang.

\section{HASIL}

1. Univariat

Gambaran Pemilihan Tempat Persalinan oleh ibu bersalin di wilayah puskesmas Tapin utara 
Dinamika Kesehatan Jurnal Kebidanan dan Keperawatan Vol 10 No. 1 Juli 2019 (ISSN: 2086-3454 EISSN: 2549-4058) url: http://ojs.dinamikakesehatan.unism.ac.id DOI : https://doi.org/10.33859/dksm.v10i1

Determinan Pemilihan Tempat Persalinan di PuskesmasTapin Utara

Tabel 1 Gambaran Responden berdasarkan pemilihan Tempat Persalinan oleh ibu bersalin di wilayah Puskesmas Tapin Utara tahun 2017

\begin{tabular}{cll}
\hline Tempar Persalinan & Jumlah & Presentasi (\%) \\
\hline Non Faskes & $\mathbf{3 5}$ & $\mathbf{5 6 , 5}$ \\
Rumah & 35 & 56,5 \\
Faskes & $\mathbf{2 7}$ & $\mathbf{4 3 , 5}$ \\
RS & 15 & 24,2 \\
BPM & 10 & 16,1 \\
Puskesmas & - & 0 \\
Poskesdes & 2 & 3,2 \\
\hline Total & $\mathbf{6 2}$ & $\mathbf{1 0 0}$ \\
\hline
\end{tabular}

Berdasarkan hasil peneltian pada

tabel 1 diketahui bahwa masih banyak

ibu bersalin yang memilih melahirkan

tidak difasilitas kesehatan $(56,5 \%)$.

\section{Univariat}

a. Hubungan Budaya dengan pemilihan

Tempat persalinan oleh ibu bersalin

di wilayah puskesmas Tapin Utara.

\begin{tabular}{|c|c|c|c|c|c|c|c|}
\hline \multirow[t]{3}{*}{ Budaya } & \multicolumn{4}{|c|}{ Tempat Persalinan } & \multirow{2}{*}{\multicolumn{2}{|c|}{ Total }} & \multirow{3}{*}{$\begin{array}{c}\mathbf{P} \\
\text { Value }\end{array}$} \\
\hline & \multicolumn{2}{|c|}{ Non Faskes } & \multicolumn{2}{|c|}{ Faskes } & & & \\
\hline & $\mathrm{N}$ & $\%$ & $\mathrm{~N}$ & $\%$ & $\mathrm{~N}$ & $\%$ & \\
\hline $\begin{array}{l}\text { Ada larangan dari } \\
\text { budaya untuk ibu } \\
\text { bersalin di fasilitas } \\
\text { kesehatan }\end{array}$ & 15 & 24,2 & 0 & 0 & 15 & 24,2 & 0,000 \\
\hline $\begin{array}{l}\text { Tidak ada } \\
\text { Larangan dari } \\
\text { budaya untuk ibu } \\
\text { bersalin di fasilitas } \\
\text { kesehatan }\end{array}$ & 20 & 32,2 & 27 & 43,5 & 47 & 75,8 & \\
\hline Total & 35 & 56,4 & 27 & 43,6 & 62 & 100 & \\
\hline
\end{tabular}

Berdasarkan tabel 2 diperoleh

pada ibu bersalin yang memilih

tempat persalinan di faskes pada

variabel budaya tidak ada larangan

bersalin di faskes sebanyak 27

(43,5\%). Uji Stastik diperoleh nilai

$\mathrm{P}=0,000$ berarti ada hubungan yang bermakna antara budaya dengan

pemilihan tempat persalinan.

b. Hubungan Pemeriksaan Kehamilan dengan pemilihan Tempat persalinan

oleh ibu bersalin di wilayah

puskesmas Tapin Utara.

Tabel.3 Hubungan pemeriksaan kehamilan Dengan Pemilihan Tempat Persalinan oleh Ibu Brs Di Puskesmas Tapin Utara.

\begin{tabular}{|c|c|c|c|c|c|c|c|}
\hline \multirow{3}{*}{$\begin{array}{l}\text { Pemeriksa } \\
\text { an } \\
\text { Kehamila } \\
\text { n / ANC }\end{array}$} & \multicolumn{4}{|c|}{ Tempat Persalinan } & \multirow{2}{*}{\multicolumn{2}{|c|}{ Total }} & \multirow{3}{*}{$\begin{array}{l}\mathbf{P} \\
\text { Value }\end{array}$} \\
\hline & \multicolumn{2}{|c|}{ Non Faskes } & \multicolumn{2}{|c|}{ Faskes } & & & \\
\hline & $\mathrm{n}$ & $\%$ & $\mathrm{~N}$ & $\%$ & $\mathrm{~N}$ & $\%$ & \\
\hline $\begin{array}{l}\text { Tidak } \\
\text { sesuai } \\
\text { program }\end{array}$ & 11 & 24,2 & 0 & 0 & 15 & 24, & 0,0001 \\
\hline $\begin{array}{l}\text { Sesuai } \\
\text { Program }\end{array}$ & 20 & 32,2 & 27 & 43 , & 47 & 75 , & \\
\hline Total & 35 & 56,4 & 2 & 43, & 62 & 10 & \\
\hline
\end{tabular}

semua ibu yang bersalin difaskes

melakukan ANC yang sesuai

program anjuran pemerintah sebesar

27 (43,5\%). Uji Stastik diperoleh

nilai $\mathrm{P}=0,001$ berarti ada hubungan

yang bermakna antara pemeriksaan

kehamilan / ANC dengan pemilihan

tempat persalinan.

c. Hubungan pengetahuan ibu dengan

pemilihan Tempat persalinan oleh

ibu bersalin di wilayah puskesmas

Tapin Utara.

Tabel.4 Hubungan Pengetahuan Dengan Pemilihan Tempa Persalinan oleh ibu Bersalin Di Puskesmas Tapin Utara.

$\begin{array}{llll}\text { Pengetahuan } & \text { Tempat Persalinan } & \text { Total } & \text { P }\end{array}$


Dinamika Kesehatan Jurnal Kebidanan dan Keperawatan Vol 10 No. 1 Juli 2019 (ISSN: 2086-3454 EISSN: 2549-4058)

url: http://ojs.dinamikakesehatan.unism.ac.id DOI : https://doi.org/10.33859/dksm.v10i1

Determinan Pemilihan Tempat Persalinan di PuskesmasTapin Utara

\begin{tabular}{llllllll}
\hline & \multicolumn{2}{l}{ Non Faskes } & \multicolumn{2}{l}{ Faskes } & \multicolumn{2}{c}{ value } \\
\cline { 2 - 7 } & $\mathrm{N}$ & $\%$ & $\mathrm{~N}$ & $\%$ & $\mathrm{~N}$ & $\%$ & \\
\hline Rendah & 27 & 43,5 & 4 & 6,5 & 31 & 50 & 0,000 \\
Tinggi & 8 & 12,9 & 23 & 37,1 & 31 & 50 & \\
\hline Total & 35 & 56,4 & 27 & 43,6 & 62 & 100 & \\
\hline
\end{tabular}

Berdasarkan tabel 4 diketahui

bahwa ibu yang memilih melahirkan

di non faskes, memiliki

pengetahuan rendah(43,5\%). Uji

Stastik diperoleh nilai $\mathrm{P}=0,000$

berarti ada hubungan yang

bermakna antara faktor pengetahuan

Ibu dengan pemilihan tempat

persalinan.

d. Hubungan Pendapatan dengan

pemilihan Tempat persalinan oleh

ibu bersalin di wilayah puskesmas

Tapin Utara.

Tabel.5 Hubungan pendapatan Dengan Pemilihan Tempat Persalinan Di Puskesmas Tapin Utara Kab.Tapin Tahun 2017.

\begin{tabular}{|c|c|c|c|c|c|c|c|}
\hline \multirow[t]{3}{*}{ Pendapatan } & \multicolumn{4}{|c|}{ Tempat Persalinan } & \multirow{2}{*}{\multicolumn{2}{|c|}{ Total }} & \multirow{3}{*}{$\begin{array}{c}P \\
\text { Valve }\end{array}$} \\
\hline & \multicolumn{2}{|c|}{ Non Faskes } & \multicolumn{2}{|c|}{ Faskes } & & & \\
\hline & $\mathrm{N}$ & $\%$ & $\mathrm{~N}$ & $\%$ & $\mathrm{n}$ & $\%$ & \\
\hline $\begin{array}{c}\text { > Rp. } \\
1.870 .000\end{array}$ & 18 & 29 & 9 & 14,5 & 27 & $\begin{array}{c}43, \\
5\end{array}$ & 0,154 \\
\hline $\begin{array}{c}<\text { Rp. } \\
1.870 .000\end{array}$ & 17 & 27,4 & 18 & 29,1 & 35 & $\begin{array}{c}56, \\
5\end{array}$ & \\
\hline Total & 35 & 56,4 & 27 & 43,6 & 62 & 100 & \\
\hline
\end{tabular}

Berdasarkan tabel 5 diperoleh

data masih banyak ibu bersalin yang

memilih tempat persalinan di non

faskes pendapatan keluarga >Rp.

$1.870 .000 \quad(29,1 \%) \quad$ sebanding

dengan ibu yangg memillih

melahirkan di faskes dengan pendapatan keluarga $<\mathrm{Rp}$.

1.870.000. Uji Stastik diperoleh nilai $\mathrm{P}=0,154$ berarti tidak ada

hubungan yang bermakna antara

faktor pendapatan dengan pemilihan

tempat persalinan.

e. Hubungan biaya persalinan dengan

pemilihan Tempat persalinan oleh

ibu bersalin di wilayah puskesmas

Tapin Utara.

Tabel. 6 Hubungan Biaya Persalinan Dengan Pemilihan Tempat Persalinan Di Puskesmas Tapin Utara.

\begin{tabular}{|c|c|c|c|c|c|c|c|}
\hline \multirow{3}{*}{$\begin{array}{l}\text { Biaya } \\
\text { Persalinan }\end{array}$} & \multicolumn{4}{|c|}{ Tempat Persalinan } & \multirow{2}{*}{\multicolumn{2}{|c|}{ Total }} & \multirow{3}{*}{$\begin{array}{l}P \\
\text { value }\end{array}$} \\
\hline & \multicolumn{2}{|c|}{$\begin{array}{l}\text { Non } \\
\text { Faskes }\end{array}$} & \multicolumn{2}{|c|}{ Faskes } & & & \\
\hline & $\mathrm{N}$ & $\%$ & $\mathrm{~N}$ & $\%$ & $\mathrm{~N}$ & $\%$ & \\
\hline$<$ Rp. 700.000 & 4 & 6,4 & 13 & 21,1 & 27 & $\begin{array}{l}43, \\
5\end{array}$ & 0,001 \\
\hline > Rp. 700.000 & 31 & 50 & 14 & 22,5 & 35 & $\begin{array}{l}56, \\
5\end{array}$ & \\
\hline Total & 35 & $\begin{array}{l}56, \\
4\end{array}$ & 27 & 43,6 & 62 & 100 & \\
\hline
\end{tabular}

Berdasarkan tabel 6 diketahui

bahwa setengah dari ibu melahirkan

yang memilih non faskes dalam

persalinan memiliki biaya

>700.000. Uji Stastik diperoleh nilai

$\mathrm{P}=0,001$ berarti ada hubungan yang

bermakna antara biaya persalinan

dengan pemilihan tempat

persalinan.

f. Hubungan akses ke fasilitas

Kesehatan dengan pemilihan Tempat 
Dinamika Kesehatan Jurnal Kebidanan dan Keperawatan Vol 10 No. 1 Juli 2019 (ISSN: 2086-3454 EISSN: 2549-4058)

url: http://ojs.dinamikakesehatan.unism.ac.id DOI : https://doi.org/10.33859/dksm.v10i1

Determinan Pemilihan Tempat Persalinan di PuskesmasTapin Utara

persalinan oleh ibu bersalin di

wilayah puskesmas Tapin Utara.

\begin{tabular}{lcccccc}
$\begin{array}{l}\text { Ada } \\
\text { dukungan }\end{array}$ & 32 & 51,6 & 26 & 42 & 58 & 35,5 \\
\hline Total & 35 & 56,4 & 27 & $\begin{array}{l}43, \\
6\end{array}$ & 62 & 100 \\
\hline
\end{tabular}

Berdasarkan tabel 8 diperoleh

bahwa ibu bersalin yang memilih

tempat persalinan di non faskes

paling banyak mendaapatkan

dukungan keluarga $(51,6 \%)$. Uji

Stastik diperoleh nilai $\mathrm{P}=0.439$

berarti tidak ada hubungan yang

bermakna antara faktor dukungan

keluarga dengan pemilihan tempat

persalinan

3. Analisis Multivariat

a) Seleksi bivariat

Tabel.8 Analisis determinan pemilihan tempat persalinan oleh
\begin{tabular}{lc} 
ibu bersalin di wilayah puskesmas Tapin utara \\
\hline \multicolumn{1}{c}{ Variabel } & P Value \\
\hline Budaya & 0,000 \\
Pemeriksaan Kehamilan & 0,001 \\
Pengetahuan & 0,000 \\
Pendapatan & 0,154 \\
Biaya Persalinan & 0,001 \\
Akses kefasilitas Kesehatan & 0,315 \\
Dukungan Keluarga & 0,411
\end{tabular}

g. Hubungan Dukungan keluarga

dengan pemilihan Tempat persalinan

oleh ibu bersalin di wilayah

puskesmas Tapin Utara.

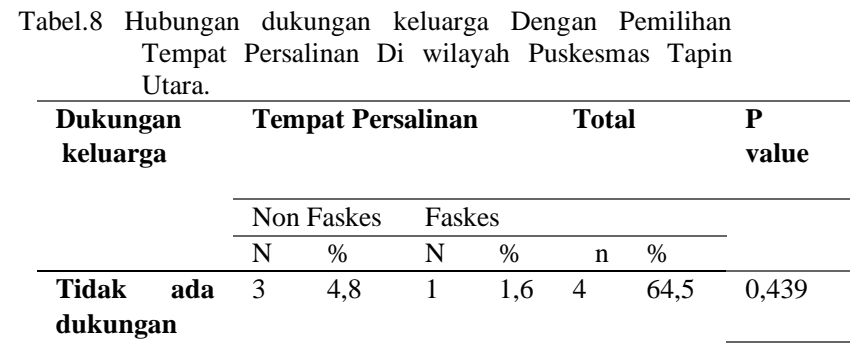

Berdasarkan hasil analisis

bivariat maka dapat disimpulkan

bahwa variabel yang memenuhi

syarat dalam analisis multivariat

adalah budaya, pengetahuan,

pendapatan dan biaya persalinan,

sedangkan untuk variabel akses ibu 
Dinamika Kesehatan Jurnal Kebidanan dan Keperawatan Vol 10 No. 1 Juli 2019 (ISSN: 2086-3454 EISSN: 2549-4058)

url: http://ojs.dinamikakesehatan.unism.ac.id DOI : https://doi.org/10.33859/dksm.v10i1

Determinan Pemilihan Tempat Persalinan di PuskesmasTapin Utara

ke fasilitas kesehatan dan dukungan

keluarga tidak ikut dalam analisis

multivariate karena mempunyai

nilai $\mathrm{p}$ value $>0,25$.

b) Pemodelan Multivariat

1) Pemodelan pertama

Tabel.9 Determinan pemilihan tempat persalinan oleh ibu bersalin di wilayah puskesmas Tapin utara

\begin{tabular}{lccl}
\multicolumn{4}{c}{ bersalin di wilayah puskesmas Tapin utara } \\
& P Value & OR & CI \\
\hline Budaya & 0,998 & 0,000 & 0,000 \\
& & & \\
Pemeriksaan Kehamilan & 0,998 & $0,000-$ & 0,000 \\
Pengetahuan & 0,001 & 0,049 & $0,008-0,296$ \\
Pendapatan & 0,801 & 0,799 & $0,141-4,540$ \\
Biaya persalinan & 0,044 & 8,602 & $1,005-70,123$ \\
& & & \\
\hline
\end{tabular}

Berdasarkanhasil pemodelan pertama analisis multivariat didapatkan bahwa nilai $\mathrm{p}$ terbesar adalah variabel budaya 0.998 dan pemeriksaan kehamilan 0,998.

2) Pemodelan Kedua

Tabel 10 Determinan pemilihan tempat persalinan oleh ibu bersalin di wilayah puskesmas Tapin utara

\begin{tabular}{|c|c|c|c|}
\hline Variabel & P Value & OR & CI \\
\hline Pemeriksaan Kehamilan & 0,998 & 0,000 & 0.000 \\
\hline Pengetahuan & 0,000 & 0,037 & $0,007-0,204$ \\
\hline Pendapatan & 0,621 & 0,665 & $0,141-4,540$ \\
\hline Biaya persalinan & 0,028 & 8,863 & $\begin{array}{l}1,273- \\
61,700\end{array}$ \\
\hline
\end{tabular}

Berdasarkan pemodelan

kedua setelah variabel budaya

dikelurkan diadapatkan bahwa perubahan OR pada masing masing variabel $<10 \%$. Dengan demikian variabel budaya bukan variable counfounding, sehingga dikeluarkan dari pemodelan.

Variabel pemeriksaan kehamilan/ANC memiliki $\mathrm{P}$ value 0,998 yang artinya masih terdapat variabel yang memiliki nilai $\mathrm{p}>0,05$, sehingga variabel ANC dikeluarkan dari pemodelan.

\section{3) Pemodelan Ketiga}

Tabel 11 Determinan pemilihan tempat persalinan oleh ibu bersalin di wilayah puskesmas Tapin utara

\begin{tabular}{llll}
\hline Variabel & P Value & OR & CI \\
\hline Pengetahuan & 0,000 & 0,037 & $0,007-0,191$ \\
Pendapatan & 0,308 & 0,473 & $0,113-1,991$ \\
Biaya persalinan & 0,009 & 11,172 & $1,820-68,574$ \\
\hline
\end{tabular}

Berdasarkan pemodelan ketiga setelah variabel ANC dikelurkan diadapatkan bahwa perubahan OR $<10 \%$. ANC bukan variabel counfounding, sehingga variabel tersebut dikeluarkan dari pemodelan.

Dari hasil pemodelan ketiga di dapatkan Variabel pendapatan 
Dinamika Kesehatan Jurnal Kebidanan dan Keperawatan Vol 10 No. 1 Juli 2019 (ISSN: 2086-3454 EISSN: 2549-4058)

url: http://ojs.dinamikakesehatan.unism.ac.id DOI : https://doi.org/10.33859/dksm.v10i1

Determinan Pemilihan Tempat Persalinan di PuskesmasTapin Utara

memiliki $\mathrm{P}$ value 0,308 yang

artinya masih terdapat variabel

yang memiliki nilai $\mathrm{p}>0,05$,

sehingga variabel pendaptan

dikeluarkan dari pemodelan

4) Pemodelan Keempat

Tabel 12 Pemodelan Keempat determinan yang
mempengaruhi pemilihan tempat persalinan
oleh ibu bersalin di wilayah puskesmas
Tapin utara

Berdasarkan didapatkan bahwa

perubahan OR pada masing-

masing variabel $<10 \%$, sehingga

variabel jenis pendapatan dapat

dikeluarkan dari pemodelan.

c) Pemodelan akhir

Dari tabel 12 dapat disimpulkan variabel yang nilai OR paling tinggi adalah biaya persalinan sebesar 11,712. Yang berarti variabel biaya persalinan merupakan variabel yang paling dominan mempengaruhi pemilihan tempat persalinan dengan Biaya persalinan < Rp. 700.000 dengan $\mathrm{OR}=11,712$.
1. Tempat persalinan

$$
\text { Hasil penelitian di wilayah }
$$
puskesmas Tapin Utara kecamatan Tapin Utara kabupaten Tapin pada persalinan bulan januari 2017 menunjukkan bahwa persalinan ibu banyak terjadi di non faskes atau rumah pasien sendiri, yaitu sebanyak 35 persalinan sedangkan di fasilitas kesehatan sebanyak 27 persalinan

Penelitian ini sejalan dengan hasil penelitian Rusnawati pada tahun 2012 dalam penelitiannya yang berjudul faktorfaktor yang mempengaruhi pemilihan tempat persalinan yang menghasilkan bahwa tempat persalinan yang paling banyak digunakan adalah rumah sendiri $51,1 \%$, dan fasilitas kesehatan sebesar $48,9 \%$.

Salah satu penyebab masih dilakukan pertolongan di non faskes di kabupaten Tapin adalah belum berjalannya secara maksimal peraturan daerah yang diajukan dinas kabupaten Tapin pada pertengahan tahun 2016. Dinas Kabupaten Tapin mengajukan Prolitda kepada pemerintah 
Dinamika Kesehatan Jurnal Kebidanan dan Keperawatan Vol 10 No. 1 Juli 2019 (ISSN: 2086-3454 EISSN: 2549-4058) url: http://ojs.dinamikakesehatan.unism.ac.id DOI : https://doi.org/10.33859/dksm.v10i1

Determinan Pemilihan Tempat Persalinan di PuskesmasTapin Utara

untuk seluruh persalinan harus dilaksanakan di fasilitas kesehatan berdasarkan Peraturan Menteri Kesehatan Nomor 43 Tahun 2016 tentang SPM Bidang Kesehatan, pada akhir bulan januari 2017 baru diterbitkan perda tentang persalinan wajib di lakukan di fasilitas kesehatan sesuai prolitda yang diajukan oleh dinas kesehatan dan bantuan jampersal bagi masyarakat yang tidak mampu, tetapi sosialisai dan penerapannya belum dilaksanakan sepenuhnya sehingga masih ada persalinan ditolong dirumah oleh tenaga kesehatan terutama bidan.

2. Budaya

Hasil penelitian menunjukkan bahwa ada hubungan yang bermakna antara faktor budaya dengan pemilihan tempat persalinan. Budaya yang dianggap melarang untuk bersalin difasilitas kesehatan yaitu larangan bagi ibu bersalin untuk meninggalkan rumah ketika melahirkan sampai 40 hari masa nifasnya. Berdasarkan Odds Ratio (OR) diperoleh nilai sebesar 2,125 artinya ibu dengan ada dukungan budaya mempunyai peluang 2 kali untuk memilih fasilitas kesehatan sebagai tempat persalinannya dibandingkan dengan ibu tidak ada dukungan dari budaya.

3. Pemeriksaan Kehamilan / ANC

Hasil analisis menyebutkkan ada hubungan yang bermakna antara pemeriksaan kehamilan / ANC dengan pemilihan tempat persalinan. Berdasarkan hasil observasi yang dilakukan oleh peneliti, ibu yang melakukan ANC sesuai dengan program akan memilih fasilitas kesehatan sebagai tempat persalinan. Semakin sering ibu melakukan pemeriksaan kehamilan, semakin banyak informasi yang dimiliki ibu terhadap kehamilan dan persalinan, selain itu juga anjuran dari tenaga kesehatan untuk bersalin di fasilitas kesehatan sangat penting, karena ada sebagian masyarakat menganggap tenaga kesehatan adalah orang yang paling mengerti tentang kesehatan.

Penelitian ini sejalan dengan 
Dinamika Kesehatan Jurnal Kebidanan dan Keperawatan Vol 10 No. 1 Juli 2019 (ISSN: 2086-3454 EISSN: 2549-4058) url: http://ojs.dinamikakesehatan.unism.ac.id DOI : https://doi.org/10.33859/dksm.v10i1

Determinan Pemilihan Tempat Persalinan di PuskesmasTapin Utara

penelitian yang dilakukan Rusnawati

(2012), bahwa yang melakukan

pemeriksaan kehamilan sesuai dengan

program mempunyai peluang 4,875 kali

untuk memilih fasilitas kesehatan sebagai

tempat persalinan.

4. Pengetahuan

Pada penelitian didapatkan hasil bahwa ada hubungan yang bermakna antara pengetahuan ibu dengan pemilihan tempat persalinan. Ibu yang mengetahui pentingnya melakukan persalinan difaskes tentu akan memilih faskes sebagai tempat persalinannya, sedangkan ibu yang berpengetahuan rendah $(43,5 \%)$ tidak mengetahui pentingnya mehirkan difaskes dan tidak mengetahui komplikasi yang mungkin terjadi dalam persalinan sehingga memilih nonfaskes dalam persalinannya

Hasil penelitian ini sejalan dengan penelitian nurjanah (2016) bahwa ada hubungan yang signifikan antara pengetahuan ibu dengan prilaku ibu dalam pemilihan tempat persalinan.

5. Pendapatan.
Pendapatan keluarga tidak

mempengaruhi dalam pemilihan tempat persalinan. Keluarga dengan pendapatan diatas ataupun dibawah UMR memilih tempat persalinan berdasarkan faktor lain yang mempengaruhi pemilihan tempat persalinan. Pada daerah pedesaan keluarga yang mempunyai pendapatan diatas UMR mereka tetap memilih bersalin di non faskes dengan alasan bisa berkumpul dengan keluarga yang memberi dukungan.yang memanfaatkan rumah sebagai tempat persalinan semakin besar.

6. Biaya Persalinan

Hasil uji statistik diperoleh nilai $\mathrm{P}=0,001$ hal ini berarti ada hubungan yang bermakna antara Biaya Persalinan dengan pemilihan tempat persalinan. Biaya persalinan masih merupakan penyebab utama alasan masyarakat memilih rumah sebagai tempat persalinan dibandingkan ke fasilitas kesehatan. Keluarga yang sudah tahu masalah kesehatan, mengupayakan keluarganya 
untuk melahirkan di fasilitas kesehatan, namun apabila biaya persalinannya terlalu tinggi, maka dengan terpaksa melahirkan di rumah dan bahkan ditolong oleh paraji, karena mengingat biayanya lebih murah dan lebih nyaman.(Cherawaty, 2014).

Ibu bersalin beranggapan bahwa biaya persalinan mahal pada fasilitas kesehatan merupakan salah satu alasan ibu dan keluarga lebih memilih persalinan dilakukan di non faskes. Dalam upaya mengatasi hambatan finansial yang dialami oleh ibu bersalin, maka pada tahun 2011 Kementrian Kesehatan melakukan upaya terobosan dengan meluncurkan paket jampersal bagi masyarakat, namun sayang diperjalanannya pada tahun 2014 program ini berhenti dikarenakan perubahan pemerintah. Tahun 2016 pemerintah mulai menggalakan kembali program jampersal bagi masyarakat tidak mampu, tetapi masyarkat masih kurang informasi atas program ini sehingga masih belum memanfaatkan secara maksimal, dan pelaksanaannyapun perlu upaya yang serius dengan cara yang luar biasa agar masyarakat dapat memanfaatkan paket jampersal ini secara optimal.

7. Akses ibu kefasilitas Kesehatan. Jarak rumah ibu ke fasilitas kesehatan berhubungan erat dengan sarana, biaya transportasi dan waktu yang dibutuhkan untuk mencapainya. Semakin dekat jarak rumah ibu dengan fasilitas keseahatan, maka semakin murah biaya yang dikeluarkan.

Hasil penelitian ini bertolak belakang dengan penelitian Ejawati, dkk(2015) di kabupaten pengandaran jawa barat yang menyebutkan ada hubungan bermakna antara pemelihan tempat persalinan dengan akses ibu ke fasilitas kesehatan.

8. Dukungan Keluarga

Hasil uji statistic diperoleh nilai $\mathrm{P}=0,315$ hal ini berarti tidak ada hubungan yang bermakna antara Dukungan keluarga dengan pemilihan 
Dinamika Kesehatan Jurnal Kebidanan dan Keperawatan Vol 10 No. 1 Juli 2019 (ISSN: 2086-3454 EISSN: 2549-4058) url: http://ojs.dinamikakesehatan.unism.ac.id DOI : https://doi.org/10.33859/dksm.v10i1

Determinan Pemilihan Tempat Persalinan di PuskesmasTapin Utara

tempat persalinan. Hal ini terjadi karena

pada ibu bersalin di faskes maupun non

faskes sama-sama mendapatkan

dukungan dari keluarga, artinya

dukungan keluarga sangat mempengaruhi

keputusan dalam menentukan tempt

persalinan.

Hasil penelitian ini didukung oleh penelitian Rusnwati (2012) yang menyebutkan ada hubungan yang bermakna anatara dukungan keluarga dengan pemilihan tempat persalinan.

\section{UCAPAN TERIMA KASIH}

Peneliti mengucapkan terima kasih sebesarbesarnya kepada Kepala Puskesmas Tapin Utara yang telah memberikan ijin dan kesempatan untuk melakukan penelitian dan kepada Rektor Universitas Sari Mulia karena telah mendukung peneliti dalam melaksanakan penelitian.

\section{DAFTAR PUSTAKA}

Kemenkes RI. 2015. Rencana Starategi Kesehatan Tahun 2015-2019. Jakarta: Kementrian Kesehatan RI

Kemenkes RI. 2016. Standar Pelayanan Minimal Kesehatan. Jakarta: Kementrian Kesehatan RI

Nurjanah,siti. 2016. Hubungan pengetahuan dan dukungan keluarga pada ibu hamil TIII dengan pemilihan tempat persalinan di kelurahan sendangmolyu kota semarang. Temu Ilmiah AIPKEMA

Rosnani, 2011.Budaya dan Faktor-Faktor Lain Yang Berhubungan DenganPemilihan Penolong Persalinan di Wilayah Kerja Puskesmas Rakit Kulim Kabupaten Indragiri Hulu Provinsi Riau Tahun 2011. Skripsi, FKM-UI

Rusnawati. 2012. Faktor-faktor yang berhubungan dengan pemilihan tempat persalinan di wilayah kerja puskesmas Negara kec. Daha Utara Kab. HSS Prov. Kalimantan Selatan Tahun 2016.Skripsi, FKM-UI

Wulan sari, triana, dkk (2010). Analisis spasial pemilihan tempat pertolongan persalinan di kelurahan sindang molyu semarang tahun 2010. Jurnal Kesehatan Reproduksi Vol.1. No 3, Agustus 2011: 113-124. 